\title{
INVESTIMENTO EM CAPITAL FIXO EM MINAS GERAIS NO PERÍODO DE 2005-2009: GARGALO NA INFRAESTRUTURA DE TRANSPORTE RODOVIÁRIO E NA PRODUÇÃO DE BENS DE CAPITAL MAIS ELABORADOS
}

Thiago Rafael Corrêa de Almeida'

\section{Resumo}

Este trabalho tem o objetivo de realizar um mapeamento dos investimentos ou, na linguagem mais técnica, da Formação Bruta de Capital Fixo (FBCF) em Minas Gerais no período 2005-2009. A metodologia utilizada para esse propósito tem como referência os resultados do cálculo da FBCF pela Fundação João Pinheiro (FJP) e outras fontes de dados complementares. De forma resumida, pretende-se detalhar os investimentos com relação a sua origem, uso e composição; quantificar os investimentos públicos pelo estado; analisar o peso dos investimentos em infraestrutura e identificar possíveis gargalos para o estabelecimento de políticas públicas. Na medida do possível, buscou-se caracterizar o comportamento da FBCF por meio das teorias econômicas dos determinantes do investimento.

Palavras-chave: Investimento, Formação Bruta de Capital Fixo (FBCF), Determinantes do Investimento, Infraestrutura, Investimento Público, Economia de Minas Gerais.

Classificação JEL: E22, E62, G11, G31.

Bacharel em Administração Pública pela Fundação João Pinheiro (FJP), pós-graduado lato sensu em Estatística com ênfase em indústria e mercado pela Universidade Federal de Minas Gerais (UFMG), Especialista em Políticas Públicas e Gestão Governamental (EPPGG). Trabalha na Fundação João Pinheiro no Centro de Estatística e Informações (CEI) integrando a equipe de contas regionais (responsável pelo indicador do PIB trimestral de Minas Gerais, estudos setoriais de conjuntura econômica e membro na elaboração da Tabela de Recursos e Usos de Minas Gerais). Email: thiago.almeida@fjp.mg.gov.br 


\section{INTRODUÇÃO}

Este trabalho tem o propósito de realizar uma análise descritiva e interpretativa dos investimentos (ou da Formação Bruta de Capital Fixo - FBCF) em Minas Gerais no período 2005-2009. Pretende-se caracterizar o padrão e o comportamento dos investimentos no estado embasado nas diversas teorias econômicas que tratam do assunto: desde a abordagem clássica e neoclássica, passando pela teoria keynesiana, até as abordagens mais atuais que tratam de outros fatores como a vulnerabilidade externa, a capacidade de inovação e a influência do investimento público sobre o privado.

Assim, além de determinar a taxa de investimento total do estado em cada ano do período de referência, pretende-se: quantificar a parcela do investimento cuja origem é importada (internacional ou interestadual) ou que foi gerada dentro do próprio estado; detalhar, na medida do possível, os investimentos públicos realizados considerando os gastos da administração direta e a contribuição das empresas controladas pelo estado; analisar o peso dos investimentos em infraestrutura na economia mineira; identificar os produtos que mais contribuíram para o nível de investimento em Minas Gerais e, por último, observar o comportamento da FBCF no período de ocorrência da crise econômica mundial (2008-2009). Portanto, as perguntas que norteiam a realização do trabalho são: como estão os investimentos em capital fixo no estado no período 2005-2009? Desse diagnóstico, quais gargalos podem ser apontados para o estabelecimento de políticas públicas?

$\mathrm{O}$ artigo está estruturado em cinco partes. Além dessa seção introdutória com o detalhamento dos objetivos, a seção seguinte (2) traz o referencial teórico com os determinantes do investimento e será fundamental para o diagnóstico e interpretação da FBCF estadual. A seção 3 evidencia a origem das informações, das fontes de dados utilizadas e o nível de desagregação dos produtos. Finalmente, a seção 4 traz a tabulação e a análise das informações obtidas e os principais resultados e conclusões são apresentados na seção 5.

\section{REFERENCIAL TEÓRICO}

Esta seção tem o intuito de elencar e descrever os fatores intervenientes que afetam a decisão de realização do investimento e servirá como base para 
a interpretação da Formação Bruta de Capital Fixo (FBCF) em Minas Gerais no período de referência (2005-2009). Assim, pretende-se pontuar o conjunto de variáveis ou de condicionantes que afetam a taxa de investimento tendo como referencial as diversas teorias econômicas que abordam o assunto.

Com relação às teorias que elencam os fatores determinantes do investimento podemos citar a visão clássica, a visão neoclássica, o pensamento de Keynes e de Kalecki, passando pela abordagem pós-keynesiana até o pensamento da aderência aos ciclos de liquidez internacional no que tange à vulnerabilidade externa, que já se enquadra nos desenvolvimentos mais recentes da teoria do investimento.

De acordo com a visão clássica acerca dos investimentos, toda produção geraria uma renda de mesmo valor, de maneira que tudo que foi produzido teria sua destinação garantida pela Lei de Say (GRASEL, 1996). Foi baseada nessa lei, de que a oferta agregada da economia determinaria o nível de produção, que a escola clássica concluiu que o limite para a acumulação de capital estaria relacionado com os recursos disponíveis interpretados como a própria poupança. Assim, considerando que o investimento era realizado com recursos próprios e de terceiros, os clássicos concluíram que a demanda não representaria qualquer empecilho ao crescimento da produção (GRASEL; SANTANA, 1995). Portanto, na visão clássica, os recursos disponíveis sempre antecederiam os investimentos, isto é, na relação de causalidade entre poupança e investimento conclui-se a precedência da taxa de poupança em relação aos investimentos.

No entanto, essa situação começou a mudar a partir da crise de 1929, quando foram postos em cheque a Lei de Say e os postulados da economia clássica. Neste cenário, dois economistas se destacaram na tentativa de explicar os acontecimentos que antecederam a Grande Depressão (crise de 1929): Keynes e Kalecki. Com estes dois economistas o efeito de causalidade entre poupança e investimento, destacado pela teoria clássica, se alterou: o investimento passou a ser visto como criador e não exclusivamente como resultante da poupança.

Na versão definitiva de sua teoria, Kalecki diverge claramente do pensamento clássico de que os recursos poupados é que financiam o investimento. $\mathrm{Na}$ verdade, o economista afirma exatamente o contrário: o investimento e consumo dos capitalistas são os determinantes do lucro e, sendo assim, 
também da poupança. $\mathrm{O}$ autor argumenta que o investimento é uma variável ex-ante, exatamente pelo fato do lucro (ex-post) ser determinado pelos gastos dos capitalistas. Assim, sendo a poupança a parte do lucro não gasta e sendo esta variável ex-post, constata-se que a relação poupança e investimento, dada da forma clássica, é duvidosa. Primeiro, pelo fato de que uma variável posterior não pode explicar uma anterior. E segundo, porque existe a possibilidade de haver investimento sem que haja uma poupança prévia, já que o investimento pode ser alavancado pela disponibilidade de crédito e pela capacidade de endividamento (MIGLIOLI, 1986). Explicitando esses argumentos, Kalecki sintetizou quatro fatores como determinantes das decisões de investimento: a acumulação interna de capital pelas empresas, as variações nos lucros, as variações no estoque de capital fixo e, por último, a inovação tecnológica. Ao considerar a questão do aperfeiçoamento tecnológico o autor, indiretamente, antecipou outra questão fundamental para a realização dos investimentos: a importância de um Sistema de Inovações (SI) consolidado.

Já na visão de Keynes, dois fatores seriam fundamentais na determinação do investimento: a Eficiência Marginal do Capital (EMC) ${ }^{2}$ e a taxa de juros. A EMC dependeria das expectativas de receitas, resultando da diferença entre o rendimento esperado e o preço de oferta do capital. Em outras palavras, a EMC poderia ser interpretada como uma espécie de taxa interna de retorno do investimento se esta pudesse ser "efetivamente" prevista em um contexto de incerteza não probabilística. Já a taxa de juros seria definida pela preferência pela liquidez e pela quantidade de moeda em circulação (GRASEL, 1996). Em sua análise, Keynes sempre considerou a importância dos riscos (do tomador e do transferidor de empréstimos) e da influência das expectativas incertas e imprevisíveis de curto e longo prazo na determinação da taxa de investimento. Até por isso, o autor sempre rejeitou o axioma ergódico da teoria clássica, isto é, a possibilidade do futuro ser relativamente previsível e "calculado" probabilisticamente a partir de dados do presente e do passado (DAVIDSON, 1999). Foi neste contexto que a Lei de Say (a preponderância da oferta agregada na determinação do nível de produção) foi contestada de forma mais incisiva pelo Princípio da

2 Keynes definiu a Eficiência Marginal do Capital (EMC) como "a taxa de desconto que tornaria o valor presente do fluxo de anuidades das rendas esperadas desse capital, durante toda a sua existência, exatamente igual ao seu preço de oferta" (KEYNES, 1982, p. I I5). 
Demanda Efetiva $(\mathrm{PDE})^{3}$, que conferia um papel mais decisivo à demanda agregada ao invés do nível de capacidade produtiva. Daí decorre o fato da teoria keynesiana sempre ter justificado a intervenção do governo na economia em momentos de crise, de forma a minimizar os riscos e incertezas, dada a sua capacidade de interferência na demanda agregada (GRASEL; SANTANA, 1995).

Especificamente em relação à teoria neoclássica do investimento, pode-se dizer que sua origem esteve vinculada aos estudos de Jorgenson por volta de 1963. O principal objetivo desta teoria foi analisar o nível ótimo de capital, considerando a interferência de variáveis como: a taxa de juros, o preço dos bens de capital, o valor de mercado das ações, o nível de impostos e subsídios incidentes sobre os investimentos, e a política fiscal preponderante no período. Além de considerar a taxa de juros como uma variável importantíssima na determinação da taxa de investimento, os neoclássicos argumentavam que verificar o nível ótimo de capital implicaria em analisar o nível ótimo do investimento. Para isso posicionavam em favor do critério de otimização do retorno líquido da empresa que, entre outras variáveis, considerava o efeito do preço do produto da empresa; a função de produção; o salário dos trabalhadores envolvidos, a quantidade de funcionários e o preço das máquinas e dos equipamentos (dispêndio da empresa) como fatores intervenientes (VILAR; CORREA; CAMPOS, 2004). Todavia, a abordagem neoclássica foi criticada por uma série de argumentos que criticavam a sua inconsistência teórica, como o fato de considerar valores ótimos de capital e de trabalho constantes, a controvérsia sobre a elasticidade do produto e também devido a pouca preocupação com as expectativas dos agentes econômicos envolvidos (NASCIMENTO, 2006).

Tendo em vista as diferentes abordagens teóricas até aqui apresentadas, os desenvolvimentos mais recentes da teoria do investimento conferiram destaque a outras questões como: a influência do cenário externo (vulnerabilidade externa) e de um Sistema de Inovações (SI) desenvolvido, a interferência do investimento público para o resultado global da taxa de

\footnotetext{
"O PDE atribui à demanda agregada a principal responsabilidade pela determinação do nível de atividade da economia. Em outras palavras, o que determina a quantidade produzida de um determinado bem não é a capacidade produtiva, mas sim a demanda efetivamente existente para este bem. A produção só é capaz de gerar uma renda equivalente se integralmente realizada. Portanto, é importante perceber que o PDE nos explica que, na sociedade mercantil, não se produz o que se pode, mas para o nível de demanda efetiva existente" (GRASEL; SANTANA, 1995, p. 7I).
} 
investimento e a constatação da irreversibilidade envolvida na tomada de decisão ao investir.

A Abordagem de Opções de Pindyck e Solimano (1993), por exemplo, apontou a decisão de investimento em um contexto de incerteza como um constante exercício de uma espécie de opção de compra: a de esperar por uma nova informação. Nessa abordagem, o agente econômico procuraria equilibrar o valor de espera por uma nova informação com o custo de oportunidade de adiar a decisão de investimento (busca pelo timing ideal). As implicações acerca da efetividade e da prescrição de políticas públicas pró-investimento são evidentes com o tratamento dado por Pindyck e Solimano (1993). Enquanto a teoria neoclássica trouxe previsões extremamente otimistas a respeito da efetividade de políticas econômicas, como a redução da taxa de juros e a contenção de impostos para o estímulo dos investimentos, a Abordagem de Opções trouxe mais realismo e praticidade a esses tipos de recomendações. Os autores ainda demonstraram que o investimento privado, em muitos países da América Latina, esteve negativamente relacionado com o nível e com a variação da taxa de inflação (proxy para incerteza) e da taxa de câmbio; e que o investimento público era muitas vezes reduzido na presença de um quadro de crise fiscal.

É exatamente na relação do investimento público sobre a taxa de investimento total da economia que a polêmica e a complexidade sobre o assunto se acentuam, já que o investimento realizado pelo setor público apresenta uma influência ambígua sobre o comportamento do investimento privado. A interferência positiva e de complementaridade do investimento público sobre o privado é conhecida como efeito crowding-in e se manifesta, muitas vezes, quando os gastos governamentais se traduzem em investimentos de infraestrutura (como transportes, comunicações e energia elétrica) que acabam contribuindo para o aumento da produtividade geral do capital privado. Todavia, a ampliação dos gastos públicos com investimento pode, devido à atuação dos mecanismos de transmissão monetária, resultar na elevação da taxa de juros e na competição (entre o setor público e privado) por recursos financeiros dados no mercado. A redução da disponibilidade de crédito direcionada ao setor privado diante do aumento do custo de captação do empréstimo pode desestimular os investimentos privados, traduzindo-se na influência negativa ou de substituição do investimento público sobre o privado (efeito crowding-out) (JACINTO; RIBEIRO, 1998). 
Por fim, os modelos mais recentes sobre os determinantes do investimento tentaram considerar a conjuntura econômica externa e o grau de vulnerabilidade dos países frente às mudanças no sistema financeiro internacional. Resende e Amado (2007), por exemplo, argumentaram que as economias em desenvolvimento, por possuírem um menor aprimoramento relativo do seu Sistema de Inovações (SI), teriam taxas de investimento e de crescimento econômico mais suscetíveis aos ciclos do sistema financeiro internacional. Por isso, os autores acrescentaram a teoria do investimento fatores institucionais capazes de capturar o grau de vulnerabilidade externa dos países e uma variável capaz de refletir os efeitos dos ciclos do sistema financeiro mundial, como a liquidez internacional.

Em que pese às semelhanças e diferenças entre as diversas teorias e modelos explicativos citados anteriormente sobre os determinantes do investimento, pode-se concluir que, resumidamente, este se encontra relacionado com uma ou mais das seguintes variáveis explicativas: nível de poupança na economia; nível de produto ou grau de utilização da capacidade produtiva da economia; disponibilidade de crédito; taxa de juros real e eficiência marginal do capital; credibilidade nas instituições como fator favorável na decisão pró-investimento; grau de incerteza na economia (em geral representado pelas oscilações do nível de preços ou da taxa de câmbio); taxa de câmbio real; liquidez internacional e vulnerabilidade externa; capacidade de inovação; nível de carga tributária; e a interferência do investimento do setor público que pode ter um papel de complementaridade ou de substituição do investimento privado.

\section{DADOS}

A análise dos investimentos em capital fixo ocorridos em Minas Gerais no período 2005-2009 teve como fonte de dados principal o cálculo da FBCF desenvolvida pela Fundação João Pinheiro (2011), que utilizou a Tabela de Recursos e Usos (TRU-MG) ${ }^{4}$ do ano de 2005 como estrutura de referência e, por meio de índices de volume e indicadores de preço específicos, evoluiu os produtos típicos da TRU considerados como Formação Bruta de Capital

\footnotetext{
A Tabela de Recursos e Usos (TRU) apresenta o retrato da economia do estado nas três óticas comumente mencionadas no cálculo do PIB mostrando o fluxo, o encadeamento e as relações entre os diferentes setores através da ótica da produção, da despesa e da renda.
} 
Fixo até o ano de 2009. ${ }^{5}$ Nesta metodologia, o registro contábil da FBCF ocorreu em relação a 11 produtos:

- Bovinos;

- Outros produtos da agricultura, silvicultura e exploração florestal;

- Outros produtos da pecuária e pesca;

- Produtos de metal;

- Máquinas e equipamentos;

- Máquinas, aparelhos e materiais elétricos;

- Automóveis, camionetas, utilitários, caminhões e ônibus;

- Outros equipamentos de transporte;

- Móveis, produtos de madeira e artigos diversos;

- Construção;

- Serviços prestados as empresas.

Para além da utilização dos dados oriundos da evolução da FBCF dos 11 produtos mostrados acima e nas três esferas de análise (contribuição interna, interestadual e internacional) conforme a metodologia desenvolvida pela Fundação João Pinheiro, também buscou-se outras informações adicionais para o complemento da análise dos investimentos em Minas Gerais no período 2005-2009. Dessa forma, realizou-se uma pesquisa bibliográfica para a aquisição de informações acerca dos gastos em investimento da administração direta de Minas Gerais e das empresas estatais; das taxas de juros para o período em análise; dos setores que mais investiram no estado; e uma breve análise dos investimentos em infraestrutura principalmente no que se refere aos setores de transporte, saneamento básico e energia elétrica. $\mathrm{Na}$ medida do possível, comparou os investimentos em infraestrutura de Minas Gerais com o padrão brasileiro de investimento.

É importante salientar que, embora este método de evolução e projeção (de volume e preço) aplicado sobre os valores de um ano base (no caso 2005) possa ser criticado, este procedimento pode ser embasado na antiga metodologia de cálculo do agregado realizada pelo IBGE (Instituto Brasileiro de Geografia e Estatística). Porém, atualmente o procedimento de cálculo definitivo deste agregado deriva da atualização da Tabela de Recursos e Usos (TRU) para cada ano de interesse. Em relação a esse aspecto, pode-se dizer que as informações para a FBCF de 2006, 2007, 2008 e 2009 nesta metodologia são preliminares no sentido de que não resultaram de um processo de equilíbrio (entre oferta e demanda) típico de uma TRU. A construção de uma TRU nestes anos poderá levar a alteração dos resultados apresentados. Até em função da possibilidade de construção de outras Tabelas de Recursos e Usos mais atualizadas os dados não foram evoluídos para os anos mais recentes (20 I 0-20 I 4), tendo em vista que o IBGE encontra-se em processo de atualização metodológica e mudança de referência do Sistema de Contas Nacionais. 
As informações acerca do investimento público em Minas Gerais, tanto da administração direta tanto do orçamento de investimento das empresas estatais foram obtidas através da Secretaria de Estado de Planejamento e Gestão (SEPLAG). Tais informações foram retiradas do Relatório Resumido de Execução Orçamentária (Demonstrativo do Resultado Primário) e dos Quadros Consolidados de Detalhamento dos Investimentos das Empresas controladas pelo Estado presentes no Orçamento das estatais (SEPLAG, 2010). Assim, além de um detalhamento acerca de qual parcela do investimento é importada e qual parcela é produzida internamente, as informações disponibilizadas permitirão o dimensionamento da participação do investimento público (governo de Minas Gerais mais empresas estatais) no total da FBCF do estado.

\section{RESULTADOS}

Antes da apresentação dos resultados em termos dos 11 produtos da FBCF destacados na metodologia de cálculo da Fundação João Pinheiro (2011), convém disponibilizar a informação obtida em termos da taxa de investimento e dos juros para uma análise em termos daquilo que a discussão econômica estabelece para a relação entre investimento e juros. A Tabela 1 abaixo traz a taxa de investimento da economia mineira (a razão entre a FBCF corrente e o PIB ${ }^{6}$ em cada ano de referência) e a taxa de juros: taxa SELIC (taxa do Sistema Especial de Liquidação e Custódia) estabelecida pelo Banco Central (2010) e a TJLP (Taxa de Juros de Longo Prazo) disponibilizada pelo BNDES (2010).

Conforme destacado na literatura econômica, tanto pela teoria clássica e neoclássica quanto também pela teoria keynesiana, a relação esperada entre investimento econômico e taxa de juros é uma relação inversa, isto é, quando se abaixa a taxa de juros espera-se um aumento na FBCF total da economia. Em que pese as semelhanças e diferenças entre as teorias, no caso da teoria de Keynes a escolha de investimento nasce de uma relação entre a taxa de juros e a Eficiência Marginal do capital (EMC) e a teoria clássica coloca a taxa de juros como elemento regulador da relação entre poupança e investimento global, o fato é que analisando os dados para eco-

Produto Interno Bruto. 
nomia mineira constata-se que os mesmos são coerentes com as proposições teóricas: ocorre um rebaixamento da taxa de juros ao longo do período 2005-2008 acompanhado de um aumento na FBCF - choque na oferta de recursos (coeficiente de correlação de Pearson entre a taxa de investimento e taxa SELIC = - 0,925). No entanto, para o ano de 2009, a queda na taxa de juros não repercute na elevação da FBCF. A crise econômica em 2009 explica esse resultado pelo encolhimento da demanda (choque de demanda).

Tabela 1 - Taxa de investimento (\% FBCF/PIB) em Minas Gerais e juros no período 2005-2009

\begin{tabular}{c|c|c|c|c|c}
\hline Ano & $\begin{array}{c}\text { FBCF Total } \\
\text { corrente } \\
\text { (R\$ Milhões) }\end{array}$ & $\begin{array}{c}\text { PIB corrente } \\
\text { (RS Milhões) }\end{array}$ & $\begin{array}{c}\text { Taxa de inves- } \\
\text { timento } \\
\text { (\% FBCF/PIB) }\end{array}$ & $\begin{array}{c}\text { Média da } \\
\text { Taxa SELIC } \\
\text { (\% a.a) }\end{array}$ & $\begin{array}{c}\text { Média } \\
\text { TJLP } \\
\text { (\% a.a) }\end{array}$ \\
\hline $\mathbf{2 0 0 5}$ & $31.270,22$ & $192.639,26$ & 16,23 & 19,24 & 9,75 \\
\hline $\mathbf{2 0 0 6}$ & $36.309,73$ & $214.753,98$ & 16,91 & 15,65 & 7,88 \\
\hline $\mathbf{2 0 0 7}$ & $43.047,48$ & $241.293,05$ & 17,84 & 12,12 & 6,38 \\
\hline $\mathbf{2 0 0 8}$ & $52.912,34$ & $282.522,32$ & 18,73 & 12,20 & 6,25 \\
\hline $\mathbf{2 0 0 9}$ & $46.403,95$ & $285.502,23$ & 16,25 & 10,34 & 6,13 \\
\hline $\begin{array}{c}\text { Total } \\
\mathbf{2 0 0 5 - 2 0 0 9}\end{array}$ & $\mathbf{2 0 9 . 9 4 3 , 7 2}$ & $\mathbf{1 . 2 1 6 . 7 1 0 , 8 4}$ & $\mathbf{1 7 , 2 5}$ & $\mathbf{1 3 , 9 1}$ & $\mathbf{7 , 2 8}$ \\
\hline
\end{tabular}

Fonte: Elaboração própria com base em informações disponibilizadas em FUNDAÇÃO JOÃO PINHEIRO (2011), BNDES (2010) e Banco Central (2010).

Analisando a economia mineira em termos da contabilização dos 11 produtos típicos na geração dos investimentos, percebe-se que os produtos com maior peso participativo no total da FBCF no período 2005-2009 foram: Construção Civil (45,02\%); Automóveis, camionetas, utilitários, caminhões e ônibus (17,98\%); Máquinas, aparelhos e materiais elétricos $(15,70 \%)$ e Máquinas e equipamentos $(8,09 \%)$. Em termos da origem dos investimentos, a FBCF industrial correspondeu a 94,03\%, o que é natural tendo em vista o peso da construção civil e dos bens de capital na composição dos investimentos. Já a FBCF ligada ao setor agropecuário representou 5,73\%. Aparentemente, esse valor pode parecer um valor baixo, mas é bastante razoável se considerarmos a contribuição do efetivo de bovinos (reprodutor e leiteiro) nos investimentos estaduais (3,80\%). A Tabela 2 abaixo mostra a 
composição dos investimentos para o período completo (2005-2009) e para cada um dos anos de referência.

Tabela 2 - Participação Relativa por produto na FBCF Total (em \%), em Minas Gerais, no intervalo 2005-2009

\begin{tabular}{l|c|c|c|c|c|c}
\hline \multirow{2}{*}{ Atividades/Setores } & \multicolumn{5}{c}{ Participação Relativa na FBCF (\%) } \\
\cline { 2 - 7 } & $\mathbf{2 0 0 5}$ & $\mathbf{2 0 0 6}$ & $\mathbf{2 0 0 7}$ & $\mathbf{2 0 0 8}$ & $\mathbf{2 0 0 9}$ & $\begin{array}{c}\text { Total } \\
\mathbf{2 0 0 5}-\mathbf{2 0 0 9}\end{array}$ \\
\hline $\begin{array}{l}\text { Outros produtos da agricultura, } \\
\text { silvicultura e exploração } \\
\text { florestal }\end{array}$ & 1,71 & 1,44 & 1,31 & 1,39 & 2,55 & 1,69 \\
\hline Bovinos & 4,38 & 4,18 & 3,60 & 3,31 & 3,85 & 3,80 \\
\hline $\begin{array}{l}\text { Outros produtos da pecuária e } \\
\text { pesca }\end{array}$ & 0,25 & 0,23 & 0,22 & 0,22 & 0,27 & 0,24 \\
\hline Total Agropecuária & $\mathbf{6 , 3 5}$ & $\mathbf{5 , 8 4}$ & $\mathbf{5 , 1 3}$ & $\mathbf{4 , 9 2}$ & $\mathbf{6 , 6 7}$ & $\mathbf{5 , 7 3}$ \\
\hline
\end{tabular}

\begin{tabular}{|c|c|c|c|c|c|c|}
\hline Produtos de metal & 3,35 & 2,59 & 2,74 & 2,64 & 2,32 & 2,69 \\
\hline Máquinas e equipamentos & 8,28 & 7,31 & 8,36 & 8,77 & 7,58 & 8,09 \\
\hline $\begin{array}{l}\text { Máquinas, aparelhos e } \\
\text { materiais elétricos }\end{array}$ & 16,87 & 17,06 & 15,32 & 16,12 & 13,72 & 15,70 \\
\hline $\begin{array}{l}\text { Automóveis, camionetas, } \\
\text { utilitários, caminhões e ônibus }\end{array}$ & 13,56 & 16,33 & 16,88 & 21,38 & 19,38 & 17,98 \\
\hline $\begin{array}{l}\text { Outros equipamentos de } \\
\text { transporte }\end{array}$ & 2,77 & 2,97 & 3,08 & 3,10 & 2,49 & 2,89 \\
\hline $\begin{array}{l}\text { Móveis, produtos de madeira e } \\
\text { artigos diversos }\end{array}$ & 2,95 & 1,29 & 1,44 & 1,43 & 1,56 & 1,66 \\
\hline Construção & 45,65 & 46,35 & 46,80 & 41,41 & 46,02 & 45,02 \\
\hline Total Indústria & 93,42 & 93,9 & 94,62 & 94,85 & 93,07 & 94,03 \\
\hline $\begin{array}{l}\text { Serviços prestados às } \\
\text { empresas (Total Serviços) }\end{array}$ & $\mathbf{0 , 2 3}$ & 0,25 & 0,24 & 0,23 & 0,26 & 0,24 \\
\hline
\end{tabular}

Total \begin{tabular}{|l|l|l|l|l|l|}
100,00 & 100,00 & 100,00 & 100,00 & 100,00 & 100,00 \\
\hline
\end{tabular}

Fonte: Adaptado de FUNDAÇÃO JOÃO PINHEIRO (2011) p.28. 
O dimensionamento da FBCF do segmento de construção civil constitui-se em um ponto positivo para a economia mineira tendo em vista que, os investimentos em infraestrutura e habitações residenciais, exercem uma influência favorável sobre outras atividades e setores. Essa relação de interdependência estrutural que o setor de construção guarda com as demais atividades possibilita um encadeamento para frente e para trás que repercute na geração de valor no transcorrer das cadeias e etapas produtivas, e que pode contribuir de maneira indireta para a geração de emprego e renda (PASTORE, 1998). De fato, de acordo com Teixeira e Carvalho (2005):

\begin{abstract}
“[...] os investimentos em construção produzem resultados eficientes e se espalham pelos demais setores de atividades que lhes são fornecedores de insumos ou compradores do seu produto, garantindo diferenciais de produtividade e economias externas que justificam a alocação prioritária de recursos na indústria construtiva. $\mathrm{O}$ argumento usado para definir a indústria da construção civil como setor econômico de importância estratégica é o seu tamanho e impacto direto na economia, bem como sua importância indireta e induzida para o desenvolvimento.” (TEIXEIRA; CARVALHO, 2005, p.11).
\end{abstract}

Ainda na análise dos produtos, é interessante destacar o aumento na participação relativa de Automóveis, camionetas, utilitários, caminhões e ônibus; que aumentou a sua parcela na FBCF Total de 13,56\% (em 2005) para 21,38\% (em 2008), sofrendo uma pequena inflexão no ano de 2009 (Tabela 2). Essa constatação é importante, pois evidencia o problema na infraestrutura de transporte rodoviário do estado. Com a situação precária das estradas e rodovias estaduais (CNT, 2005 apud TORRES, 2006), o incremento cada vez mais intenso de veículos ao mesmo tempo em que os gastos com investimentos na infraestrutura de transportes se mantêm aquém do necessário, sinaliza para um problema grave na logística em Minas Gerais.

A condição inadequada das estradas mineiras pode ser ilustrada pelo trabalho de Morais e Guimarães (2014), que traz informações da proporção de rodovias consideradas em estado "ótimo" ou "bom" em Minas Gerais comparativamente a outros estados da federação - com base na pesquisa da Confederação Nacional dos Transportes (CNT) de Rodovias -, e con- 
siderando o estado geral das rodovias, a pavimentação e a sinalização das estradas no ano de 2007, ano intermediário da análise dos investimentos em capital fixo em Minas Gerais proposta neste artigo. Entre as dez regiões mostradas no trabalho, Minas Gerais ocupou a pior posição no que se refere à pavimentação, a quarta pior colocação no quesito sinalização (à frente apenas de Goiás, Distrito Federal e Bahia) e o segundo pior posicionamento em relação ao estado geral de conservação das rodovias (a frente apenas da Bahia). A Tabela 3 abaixo ilustra esses resultados.

Tabela 3 - Proporção de rodovias consideradas em estado "ótimo" ou "bom" (\%) em Minas Gerais e estados selecionados no que se refere ao estado geral de conservação, pavimentação e sinalização em 2007

\begin{tabular}{|c|c|c|c|c|c|c|}
\hline \multirow[b]{2}{*}{ Estados } & \multicolumn{2}{|c|}{ Conservação Geral } & \multicolumn{2}{|c|}{ Pavimentação } & \multicolumn{2}{|c|}{ Sinalização } \\
\hline & $\begin{array}{c}\text { Propor- } \\
\text { ção (\%) } \\
\text { estado } \\
\text { "ótimo" } \\
\text { ou "bom" }\end{array}$ & $\begin{array}{l}\text { Ranking } \\
\text { em } 2007\end{array}$ & $\begin{array}{c}\text { Propor- } \\
\text { ção (\%) } \\
\text { estado } \\
\text { "ótimo" } \\
\text { ou "bom" }\end{array}$ & $\begin{array}{l}\text { Ranking } \\
\text { em } 2007\end{array}$ & $\begin{array}{c}\text { Propor- } \\
\text { ção (\%) } \\
\text { estado } \\
\text { "ótimo" } \\
\text { ou "bom" }\end{array}$ & $\begin{array}{l}\text { Ranking } \\
\text { em } 2007\end{array}$ \\
\hline São Paulo & 73,3 & 1 & 78,0 & 1 & 86,7 & 1 \\
\hline Rio de Janeiro & 33,0 & 5 & 69,9 & 2 & 52,8 & 4 \\
\hline Paraná & 48,1 & 2 & 64,4 & 4 & 68,5 & 2 \\
\hline Santa Catarina & 32,0 & 6 & 55,3 & 6 & 46,5 & 5 \\
\hline Distrito Federal & 36,6 & 4 & 57,9 & 5 & 17,8 & 9 \\
\hline Rio Grande do Sul & 46,3 & 3 & 68,7 & 3 & 56,4 & 3 \\
\hline Espírito Santo & 17,7 & 8 & 43,6 & 7 & 26,3 & 6 \\
\hline Minas Gerais & 16,1 & 9 & 36,7 & 10 & 24,7 & 7 \\
\hline Goiás & 23,5 & 7 & 40,4 & 8 & 21,3 & 8 \\
\hline Bahia & 10,3 & 10 & 38,3 & 9 & 13,6 & 10 \\
\hline
\end{tabular}

Fonte: Elaboração própria com base no trabalho de MORAIS; GUIMARÃES (2014). Adaptado conforme a Confederação Nacional dos Transportes. Pesquisa CNT de Rodovias $-17^{\circ}$ Edição.

Já o trabalho de Domingues; Magalhães e Faria (2009) traz informações estimadas/projetadas do investimento bruto em infraestrutura em Minas Gerais entre 2008-2010. A Associação Brasileira de Logística e Transporte de Carga (2009) apresenta essas informações em âmbito nacional para o 
mesmo período. É interessante observar que esse intervalo de tempo se insere no período pós-lançamento do Programa de Aceleração do Crescimento (PAC), pelo governo brasileiro, que tem como objetivo a recuperação dos investimentos públicos e privados em infraestrutura energética, logística e social-urbana no país (BRASIL, 2007).

Comparando os resultados projetados ${ }^{7} \mathrm{em}$ infraestrutura em Minas Gerais com os observados no Brasil também na era do PAC, as constatações a respeito dos investimentos no estado foram: para o período 2008-2010 a participação dos investimentos estimados em infraestrutura como percentagem do PIB em Minas Gerais foi maior do que no Brasil (4,38\% contra $2,45 \%$ ). Além disso, em termos de participação no PIB, os resultados em Minas foram relativamente melhores do que no Brasil no que tange aos agrupamentos de telecomunicações $(1,73 \%$ contra $0,41 \%)$, de energia elétrica $(1,33 \%$ contra $1,04 \%)$ e de saneamento $(0,76 \%$ contra $0,37 \%)$. No entanto, a infraestrutura no setor de transporte continua sendo o ponto fraco da economia mineira: enquanto para o Brasil estimou-se um investimento da ordem de $0,63 \%$ do PIB, em Minas esse valor foi ainda menor $(0,56 \%$ do PIB mineiro) (ABTC, 2009; DOMINGUES; MAGALHÃES; FARIA, 2009). As Tabelas 4 e 5 abaixo sintetizam a composição desses investimentos em termos dos agrupamentos de infraestrutura para o Brasil e Minas Gerais, respectivamente. É interessante destacar a grande participação dos investimentos direcionados para o setor de energia elétrica no Brasil $(42,62 \%)$

\footnotetext{
Mesmo admitindo que o ideal fosse trabalhar com os investimentos em infraestrutura efetivamente realizados ao invés de valores projetados para o período, os valores estimados pela ABTC (2009) e pelo trabalho de Domingues; Magalhães e Faria (2009) estão subestimados segundo a Associação e os próprios autores, dado que se baseiam nos "investimentos mapeados" para o período mas considerando um ajuste para baixo e antecipando, portanto, a não realização de todo o conteúdo programático do PAC (até por que a primeira versão do PAC implicou em investimentos menores do que os previstos). Ademais a obtenção dos dados efetivamente realizados não é uma tarefa trivial, pois os mesmos divergem dependendo da maneira ou agregação como a informação é coletada no SIAFI (Sistema Integrado de Administração Financeira do Governo) ou em outras fontes de dados como a Associação Brasileira Concessionárias de Rodovias (ABCR) e nos balanços estaduais; e isto dificulta a comparação em que se deseja fazer neste artigo entre Minas Gerais e Brasil. Como foi utilizada a mesma agregação pela ABTC e no trabalho de Domingues; Magalhães e Faria, optou-se por mantê-los na análise. O uso da participação dos investimentos em infraestrutura no PIB é uma prática comum que pode ser visualizada em outros trabalhos como no de Campos Neto; Soares; Ferreira; Pompermayer e Romminger (20 I I) e no de Frischtak (2008) que permite comparações entre regiões e países. O trabalho de Frischtak (2008), por exemplo, traz as seguintes participações para o total dos investimentos em infraestrutura no PIB nos respectivos anos: Brasil 2,0\% (em 2007), Chile 6,2\% (em 200 I), Colômbia 5,8\% (em 200 I), Índia 5,6\% (2006-2007), China 7,3\% (em 2003), Vietnã 9,9\% (em 2003), Tailândia 15,4\% (em 2003) e Filipinas 3,6\% (em 2003).
} 
na tentativa de ampliar a matriz energética nacional ${ }^{8}$ e o peso considerável que o setor de telecomunicações vem ocupando no padrão de investimentos no estado de Minas Gerais (39,30\%) no período 2008-2010.

Tabela 4 - Composição do investimento Bruto projetado/estimado em infraestrutura (participação e \% do PIB) para o Brasil no período 2008-2010

\begin{tabular}{c|c|c}
\hline \multicolumn{3}{|c}{ BRASIL - Investimento Bruto } \\
\hline Agrupamento & Participação no total dos investimentos \% & \% do PIB Brasil \\
\hline Telecomunicações & 16,89 & 0,41 \\
\hline Energia Elétrica & 42,62 & 1,04 \\
\hline Transporte & 25,69 & 0,63 \\
\hline Saneamento & 15,25 & 0,37 \\
\hline Total & $\mathbf{1 0 0 , 0 0}$ & $\mathbf{2 , 4 5}$ \\
\hline
\end{tabular}

Fonte: Adaptado com base nas informações prestadas pela ABTC (2009) p.8.

Tabela 5 - Composição do investimento Bruto projetado/estimado em infraestrutura (participação e \% do PIB) para Minas Gerais no período 2008-2010

\section{MINAS GERAIS - Investimento Bruto}

\begin{tabular}{c|c|c}
\hline Agrupamento & Participação no total dos investimentos \% & \% do PIB MG \\
\hline Telecomunicações & 39,30 & 1,73 \\
\hline Energia Elétrica & 30,37 & 1,33 \\
\hline Transporte & 12,71 & 0,56 \\
\hline Saneamento & 17,62 & 0,76 \\
\hline Total & $\mathbf{1 0 0 , 0 0}$ & $\mathbf{4 , 3 8}$ \\
\hline
\end{tabular}

Fonte: Adaptado com base nas informações do trabalho de DOMINGUES; MAGALHÃES; FARIA (2009) p.126.

Em relação ao comportamento do investimento público no estado, a discussão gira em torno da preponderância dos efeitos crowding-in ou crowding-out destacados por Jacinto e Ribeiro (1998). No caso do estado de Minas Gerais e também analisando o Brasil como um todo existe indícios

\footnotetext{
3 Talvez em virtude da experiência com a crise energética e o "apagão" em 200 I. Apesar da alta participação dos investimentos em energia elétrica no Brasil, tudo indica que esses investimentos foram insuficientes dada a atual crise energética que se instalou na economia nacional: a forte escassez de chuvas e a geração baseada no potencial hidrelétrico prejudicada, o uso intensivos das térmicas vem contribuindo para o encarecimento da energia e a possibilidade de um novo racionamento é real (PEDROSO; VIRI, 20 I4).
} 
favoráveis à complementaridade entre o investimento público e o investimento privado. Os trabalhos de Frischtak (2008), Sanches e Rocha (2010) e Campos Neto et al. (2011) apontam para complementaridade entre estas duas parcelas do investimento para o Brasil e que pode ser estendida para o estado. A dimensão favorável ao efeito crowding-in guarda relação, principalmente, com a necessidade latente de investimento em infraestrutura em algumas áreas e setores de Minas Gerais.

Um estudo do BDMG $^{9}$ (2004) observou que a situação de infraestrutura em Minas Gerais é bastante heterogênea e diversificada, tanto em relação aos componentes quanto às condições de acesso das várias regiões e estratos da população. Os resultados acerca do estudo do banco mostraram que existe um razoável acesso aos serviços básicos de energia e telecomunicações, no entanto agravaram-se as necessidades e carências ao acesso de serviços de transportes e logística (BDMG, 2004). Com relação ao acesso aos serviços de saneamento básico os resultados são díspares e existem tanto regiões com acesso satisfatório ao serviço como regiões que ainda precisam avançar neste aspecto. Os dados acerca dos investimentos das empresas controladas pelo estado no total do período 2005-2009 traduzem, em certa medida, as conclusões da pesquisa realizada pelo BDMG: o setor de energia no estado possui uma boa margem de representatividade, o que é evidenciado pela grande parcela de participação dos investimentos da CEMIG comparativamente as demais empresas controladas pelo estado e também em relação aos gastos em energia tendo em vista as funcionalidades/especificidades das estatais. Os investimentos em saneamento básico ocupam a segunda posição em termos de participação relativa no total das empresas controladas pelo estado: a participação da COPASA no total dos investimentos só perde para a CEMIG. Nota-se ainda que os gastos com a atividade de transportes pelas estatais são irrisórios, o que mais uma vez corrobora com as conclusões do estudo realizado pelo BDMG (2004) e com os resultados apresentados anteriormente pelo trabalho de Domingues; Magalhães e Faria (2009). A Tabela 6 abaixo traz a composição (em \%) dos investimentos realizados pelas empresas controladas pelo estado conforme as informações disponibilizadas pela SEPLAG (2010). Nela fica evidente a grande participação da CEMIG (69,57\%) e da COPASA $(20,22 \%)$ no total dos investimentos das estatais no período 2005-2009.

Banco de Desenvolvimento de Minas Gerais. 
Tabela 6-Composição (em \%) dos investimentos realizados pelas empresas controladas pelo estado no período 2005-2009

\begin{tabular}{|c|c|c|c|c|c|c|}
\hline $\begin{array}{c}\text { Empresas Controladas pelo } \\
\text { Estado }\end{array}$ & 2005 & 2006 & 2007 & 2008 & 2009 & $\begin{array}{c}\text { Total } \\
\text { 2005-2009 }\end{array}$ \\
\hline $\begin{array}{l}\text { Banco de Desenvolvimento de } \\
\text { Minas Gerais S. A (BDMG) }\end{array}$ & 1,24 & 1,47 & 1,14 & 0,93 & 0,65 & 1,09 \\
\hline $\begin{array}{l}\text { Companhia de Desenvolvimento } \\
\text { Econômico de Minas Gerais } \\
\text { (CODEMIG) }\end{array}$ & 0,91 & 0,71 & 1,27 & 10,11 & 15,07 & 5,62 \\
\hline $\begin{array}{l}\text { Companhia de Gás de Minas } \\
\text { Gerais (GASMIG) }\end{array}$ & 1,97 & 5,02 & 1,34 & 0,72 & 5,04 & 2,94 \\
\hline $\begin{array}{l}\text { Companhia de Habitação } \\
\text { do Estado de Minas Gerais } \\
\text { (COHAB) }\end{array}$ & 0,03 & 0,00 & 0,00 & 0,00 & 0,00 & 0,01 \\
\hline $\begin{array}{l}\text { Companhia de Saneamento de } \\
\text { Minas Gerais (COPASA) }\end{array}$ & 22,48 & 17,87 & 20,82 & 22,32 & 17,91 & 20,22 \\
\hline $\begin{array}{l}\text { Companhia de Tecnologia da } \\
\text { Informação do Estado de Minas } \\
\text { Gerais (PRODEMGE) }\end{array}$ & 0,03 & 0,16 & 0,02 & 0,05 & 0,29 & 0,12 \\
\hline $\begin{array}{l}\text { Companhia Energética de Minas } \\
\text { Gerais (CEMIG) }\end{array}$ & 72,32 & 74,70 & 75,12 & 65,51 & 60,64 & 69,57 \\
\hline $\begin{array}{l}\text { Companhia Mineira de } \\
\text { Promoções (PROMINAS) }\end{array}$ & 0,00 & 0,01 & 0,13 & 0,01 & 0,02 & 0,03 \\
\hline $\begin{array}{l}\text { Distribuidora de Títulos e } \\
\text { Valores Mobiliários de Minas } \\
\text { Gerais S. A (DIMINAS) }\end{array}$ & 0,00 & 0,00 & - & - & - & 0,00 \\
\hline $\begin{array}{l}\text { Empresa de Assistência Técnica } \\
\text { e Extensão Rural do Estado de } \\
\text { Minas Gerais (EMATER) }\end{array}$ & 0,21 & 0,03 & 0,08 & 0,09 & 0,17 & 0,12 \\
\hline $\begin{array}{l}\text { Empresa de Pesquisa } \\
\text { Agropecuária de Minas Gerais } \\
\text { (EPAMIG) }\end{array}$ & 0,00 & 0,01 & 0,01 & 0,11 & 0,00 & 0,02 \\
\hline $\begin{array}{l}\text { Instituto de Desenvolvimento } \\
\text { Industrial de Minas Gerais } \\
\text { (INDI) }\end{array}$ & 0,01 & 0,01 & 0,01 & 0,01 & 0,00 & 0,01 \\
\hline $\begin{array}{l}\text { Minas Gerais Administração e } \\
\text { Serviços S. A (MGS) }\end{array}$ & 0,01 & 0,01 & 0,02 & 0,12 & 0,06 & 0,04 \\
\hline
\end{tabular}




\begin{tabular}{l|c|c|c|c|c|c}
\hline $\begin{array}{c}\text { Empresas Controladas pelo } \\
\text { Estado }\end{array}$ & $\mathbf{2 0 0 5}$ & $\mathbf{2 0 0 6}$ & $\mathbf{2 0 0 7}$ & $\mathbf{2 0 0 8}$ & $\mathbf{2 0 0 9}$ & $\begin{array}{c}\text { Total } \\
\mathbf{2 0 0 5 - 2 0 0 9}\end{array}$ \\
\hline $\begin{array}{l}\text { Minas Gerais Participações S.A. } \\
\text { (MGI) }\end{array}$ & 0,11 & 0,00 & 0,01 & 0,01 & 0,13 & 0,06 \\
\hline Rádio Inconfidência LTDA & 0,00 & 0,00 & 0,03 & 0,01 & 0,01 & 0,01 \\
\hline $\begin{array}{l}\text { Trem Metropolitano de Belo } \\
\text { Horizonte S.A. }\end{array}$ & 0,66 & 0,00 & 0,00 & 0,00 & 0,00 & 0,15 \\
\hline $\begin{array}{l}\text { TOTAL Empresas } \\
\text { Controladas pelo Estado }\end{array}$ & $\mathbf{1 0 0 , 0 0}$ & $\mathbf{1 0 0 , 0 0}$ & $\mathbf{1 0 0 , 0 0}$ & $\mathbf{1 0 0 , 0 0}$ & $\mathbf{1 0 0 , 0 0}$ & $\mathbf{1 0 0 , 0 0}$ \\
\hline
\end{tabular}

Fonte: Elaboração própria com base no Quadro de Detalhamento do volume dos investimentos das empresas controladas pelo estado - SEPLAG (2010).

Para se ter uma ideia do peso em que a CEMIG e a COPASA possuem nos investimentos do estado no período 2005-2009, pode-se dizer que do total da FBCF no período (R\$209.943,72 milhões correntes), a CEMIG foi responsável por $8,64 \%$ dos investimentos ou $\mathrm{R} \$ 18.132,87$ milhões correntes, enquanto a COPASA participa em 2,51\% ou 5.269,08 milhões correntes. Os grandes investimentos destas duas empresas explicam a grande participação relativa dos investimentos direcionados para energia elétrica e saneamento básico nos gastos das empresas controladas pelo estado. A Tabela 7 abaixo traz a composição (em \%) dos investimentos das empresas controladas pelo estado em termos das funções/especificações dos direcionamentos dos gastos. Nela fica evidente o grande percentual direcionado para energia elétrica $(72,51 \%)$ e também para a função de saneamento básico $(20,16 \%)$ no que tange a participação dos investimentos das empresas controladas pelo estado no total do período 2005-2009. Chama atenção, novamente, a baixa participação da função de transporte no total dos investimentos dessas empresas no período de análise (apenas $0,33 \%$ dos investimentos).

O problema relativo à falta de investimentos em infraestrutura de transporte é, sem dúvida, um dos principais gargalos ao avanço da economia mineira. A situação deste setor afeta o desenvolvimento de Minas Gerais, em virtude da perda relativa de competitividade das empresas mineiras, tanto em relação ao mercado nacional quanto ao acesso aos portos no que se refere aos produtos destinados ao exterior. ${ }^{10}$ Isto acaba contabilizando

10 As diferenças na oferta de transporte e, notadamente no transporte rodoviário, passam a ser o fator de infraestrutura mais heterogêneo e decisivo para a localização das áreas industriais em Minas Gerais. O problema se agrava 
custos adicionais aos produtos mineiros e contribui para a mitigação no tamanho do lucro das empresas do estado, favorecendo a uma redução na parcela do mesmo que seria destinada aos investimentos (BDMG, 2004). Como foi evidenciado na teoria kaleckiana, um dos fatores determinantes das decisões de investimento diz respeito, exatamente, à grande flutuação nos lucros empresariais.

Tabela 7 - Composição (em \%) dos investimentos realizados pelas empresas controladas pelo estado em termos das funções/especificações dos direcionamentos dos gastos no período 2005-2009

\begin{tabular}{l|c|c|c|c|c|c}
\hline Funções/Especificações & $\mathbf{2 0 0 5}$ & $\mathbf{2 0 0 6}$ & $\mathbf{2 0 0 7}$ & $\mathbf{2 0 0 8}$ & $\mathbf{2 0 0 9}$ & $\begin{array}{c}\text { Total } \\
\mathbf{2 0 0 5 - 2 0 0 9}\end{array}$ \\
\hline Administração & 0,15 & 0,17 & 0,05 & 9,32 & 12,17 & 4,33 \\
\hline Cultura & 0,00 & 0,00 & 0,03 & 0,01 & 0,01 & 0,01 \\
\hline Habitação & 0,03 & 0,00 & 0,00 & 0,00 & 0,00 & 0,01 \\
\hline Saneamento & 22,48 & 17,87 & 20,82 & 22,15 & 17,76 & 20,16 \\
\hline Agricultura & 0,22 & 0,04 & 0,09 & 0,21 & 0,17 & 0,15 \\
\hline Indústria & 0,92 & 0,72 & 1,15 & 0,84 & 2,58 & 1,28 \\
\hline Comércio e Serviços & 1,25 & 1,48 & 1,40 & 1,24 & 0,84 & 1,23 \\
\hline Energia & 74,29 & 79,72 & 76,46 & 66,23 & 65,68 & 72,51 \\
\hline Transporte & 0,66 & 0,00 & 0,00 & 0,00 & 0,79 & 0,33 \\
\hline Total & $\mathbf{1 0 0 , 0 0}$ & $\mathbf{1 0 0 , 0 0}$ & $\mathbf{1 0 0 , 0 0}$ & $\mathbf{1 0 0 , 0 0}$ & $\mathbf{1 0 0 , 0 0}$ & $\mathbf{1 0 0 , 0 0}$ \\
\hline
\end{tabular}

Fonte: Elaboração própria com base no Quadro de Detalhamento do volume dos investimentos das empresas controladas pelo estado - SEPLAG (2010).

Saindo do diagnóstico restrito da composição dos gastos realizados pelas empresas controladas pelo estado e analisando a totalidade dos investimentos públicos (empresas controladas pelo estado somados aos gastos da administração direta), pode-se afirmar que totalizaram $\mathrm{R} \$ 40.933,43$ milhões correntes (o que equivale a $19,50 \%$ da FBCF em todo o período). Desse total, R\$26.064,17 milhões corresponderam aos investimentos realizados pelas empresas controladas pelo estado (ou $12,41 \%$ da FBCF total); enquanto

tendo em vista o peso em que as rodovias exercem no escoamento dos produtos do estado. $\bigcirc$ trabalho de Torres (2006) informa, por exemplo, uma participação de 53\% do modal rodoviário contra 42\% do modal ferroviário na participação no total dos fluxos de carga em Minas Gerais. 
$\mathrm{R} \$ 14.869,26$ milhões corresponderam aos investimentos feitos pela administração direta (ou 7,08\% da FBCF total). Tais informações foram obtidas através do Relatório Resumido de Execução Orçamentária (Demonstrativo do Resultado Primário) e dos Quadros Consolidados de Detalhamento dos Investimentos das Empresas controladas pelo Estado presentes no Orçamento das estatais (SEPLAG, 2010). É interessante notar a queda na participação relativa dos gastos governamentais com investimento na FBCF ao longo do período de análise: a participação na FBCF caiu de 25,81\% (em 2005) para $15,15 \%$ (em 2008). Esse declínio se relaciona com a queda na participação dos gastos com investimentos das empresas controladas pelo estado no mesmo período de tempo. No entanto, no ano de 2009 ocorre um aumento dos gastos públicos de investimentos, que é evidenciado no relativo aumento na participação na FBCF entre 2008 e 2009: os gastos governamentais com investimento dão um salto de participação na FBCF de 15,15\% (em 2008) para 20,28\% (em 2009). A Tabela 8 resume as constatações acima trazendo os gastos em investimentos em termos dos valores correntes e em termos da participação percentual na FBCF das empresas controladas pelo estado e também da administração direta.

Tabela 8 - Investimento Público em Minas Gerais (empresas controladas pelo governo mineiro mais administração direta), valores correntes e \% na FBCF no período 2005-2009

\begin{tabular}{l|c|c|c|c|c|c|c}
\hline \multicolumn{2}{c|}{ Ano } & $\mathbf{2 0 0 5}$ & $\mathbf{2 0 0 6}$ & $\mathbf{2 0 0 7}$ & $\mathbf{2 0 0 8}$ & $\mathbf{2 0 0 9}$ & $\begin{array}{c}\text { Total } \\
\mathbf{2 0 0 5 - 2 0 0 9}\end{array}$ \\
\hline $\begin{array}{l}\text { Empresas } \\
\text { Controladas pelo } \\
\text { Estado }\end{array}$ & $\begin{array}{c}\text { valor (R\$ } \\
\mathbf{1 . 0 0 0 . 0 0 0 , 0 0 )}\end{array}$ & $6.045,38$ & $5.159,56$ & $4.744,01$ & $4.292,07$ & $5.823,15$ & $26.064,17$ \\
\cline { 2 - 8 } & $\%$ na FBCF & 19,33 & 14,21 & 11,02 & 8,11 & 12,55 & 12,41 \\
\hline \multirow{2}{*}{$\begin{array}{l}\text { Administração } \\
\text { Direta }\end{array}$} & $\begin{array}{c}\text { valor (R\$ } \\
\mathbf{1 . 0 0 0 . 0 0 0 , 0 0 )}\end{array}$ & $2.024,57$ & $2.712,93$ & $2.820,70$ & $3.725,67$ & $3.585,39$ & $14.869,26$ \\
\cline { 2 - 8 } & \% na FBCF & 6,47 & 7,47 & 6,55 & 7,04 & 7,73 & 7,08 \\
\hline \multirow{2}{*}{ Total } & $\begin{array}{c}\text { valor (R\$ } \\
\mathbf{1 . 0 0 0 . 0 0 0 , 0 0 )}\end{array}$ & $8.069,95$ & $7.872,49$ & $7.564,72$ & $8.017,73$ & $9.408,53$ & $40.933,43$ \\
\cline { 2 - 8 } & \% na FBCF & 25,81 & 21,68 & 17,57 & 15,15 & 20,28 & 19,50 \\
\hline
\end{tabular}

Fonte: Elaboração própria com base em informações disponibilizadas pela SEPLAG (2010) Relatório de Execução Orçamentária e Quadro de detalhamento de investimento das empresas controladas pelo estado. 
Assim, é interessante observar que, enquanto o investimento privado sofreu uma queda significativa em 2009 em virtude da crise econômica mundial ${ }^{11}$, o investimento público seguiu trajetória contrária. Este fato pode, em certa medida, estar relacionado com a teoria keynesiana que prevê a intervenção estatal na suavização dos efeitos de possíveis períodos conturbados e de instabilidade (como os períodos de crise econômica), de acordo com o Princípio da Demanda Efetiva (PDE). A citação abaixo sintetiza a visão keynesiana acerca da intervenção governamental:

“[...] O papel do governo não seria substituir os mercados privados para assumir a determinação dos investimentos. A intervenção devia ser planejada para impulsionar a demanda agregada, reduzindo assim as incertezas com relação ao futuro da economia. A política macroeconômica ideal proposta por Keynes inflaria a demanda agregada, expandindo a economia como um balão, e deixando a carga dos agentes privados as decisões de como os recursos disponíveis seriam empregados. Em resumo, o problema da demanda efetiva é que os valores dos ativos de capital, como vimos, são desfavoravelmente atingidos pelas incertezas quanto aos retornos e à sua liquidez. Impulsionando-se a demanda agregada reduzem-se os riscos e, então elevam-se os preços de demanda de cada tipo de ativo em relação a moeda. Uma onda ascendente não ergue todos os barcos, mas caberia principalmente aos agentes privados decidir quais barcos flutuariam e quais afundariam." (CARVALHO, 1999, p. 268-269).

De fato, de acordo com Carvalho (1999), a possibilidade de planejamento do governo de forma a elaborar estratégias para compensar um possível hiato no investimento privado foi previsto, no pensamento keynesiano, não só pelo fato de o governo ser mais um a tentar prever as tendências futuras, mas também por ser o principal construtor do futuro mediante o seu poder de mobilização e de interferência na demanda agregada. Assim, o papel do governo estaria relacionado com o auxílio na tentativa de criação de um ambiente macroeconômico estável e seguro para a ação dos atores privados.

\footnotetext{
' A vulnerabilidade externa dos países, dentro do contexto de conjuntura econômica internacional desfavorável, ajuda a explicar o "contágio" da crise econômica e o seu impacto na FBCF de origem privada no Brasil e em Minas Gerais no ano de 2009, conforme os desenvolvimentos mais recentes da teoria do investimento.
} 
Analisando a FBCF em Minas Gerais com relação à origem, isto é, se o investimento foi produzido dentro do estado (contribuição interna) ou se, por outro lado, veio de fora do estado (contribuição importada interestadual e internacional) pode-se dizer que para o total do período analisado (20052009) os investimentos de origem interna participaram em $79,40 \%$ no total da FBCF; enquanto que os investimentos de origem externa corresponderam a $20,60 \%(16,18 \%$ de origem interestadual e 4,42\% correspondentes às importações internacionais) (FUNDAÇÃO JOÃO PINHEIRO, 2011). A Tabela 9 mostra a contribuição de cada uma das dimensões (interna, interestadual e internacional) em cada ano de referência e para a totalidade do período (2005-2009).

Tabela 9 - Participação Relativa no que tange à origem da FBCF Total (em \%), em Minas Gerais, no período 2005-2009

\begin{tabular}{l|c|c|c|c|c|c}
\hline \multirow{2}{*}{ Origem do Investimento } & \multicolumn{6}{|c}{ Participação relativa na FBCF Total (\%) } \\
\cline { 2 - 7 } & $\mathbf{2 0 0 5}$ & $\mathbf{2 0 0 6}$ & $\mathbf{2 0 0 7}$ & $\mathbf{2 0 0 8}$ & $\mathbf{2 0 0 9}$ & $\begin{array}{c}\text { Total } \\
\mathbf{2 0 0 5 - 2 0 0 9}\end{array}$ \\
\hline Contribuição interna & 76,49 & 81,32 & 81,01 & 78,24 & 79,71 & 79,40 \\
\hline Contribuição importada interestadual & 19,58 & 14,89 & 15,40 & 15,91 & 15,94 & 16,18 \\
\hline Contribuição importada internacional & 3,93 & 3,78 & 3,59 & 5,85 & 4,36 & 4,42 \\
\hline Total & $\mathbf{1 0 0}$ & $\mathbf{1 0 0}$ & $\mathbf{1 0 0}$ & $\mathbf{1 0 0}$ & $\mathbf{1 0 0}$ & $\mathbf{1 0 0}$ \\
\hline
\end{tabular}

Fonte: Adaptado de FUNDAÇÃO JOÃO PINHEIRO (2011) p.32.

Decompondo os investimentos, quanto à origem, nos 11 produtos típicos de formação de capital fixo, pode-se afirmar que a construção civil foi aquele com maior contribuição para os investimentos de origem interna $(56,70 \%)^{12}$, o que é perfeitamente natural dada à especificidade do tipo de investimento envolvido, que compreende não apenas as habitações, mas também as obras de infraestrutura realizadas dentro da economia mineira. Daí o peso considerável da construção civil na FBCF de origem interna. Todavia, na análise dos investimentos produzidos internamente, outros produtos também se destacaram com uma proporção um pouco menor:

${ }^{12}$ A construção civil, além de ter sido o produto com maior peso na FBCF de origem interna (56,70\%) no período 2005-2009, também liderou a participação na totalidade dos investimentos realizados no mesmo período (45,02\%). 
Automóveis, camionetas, utilitários, caminhões e ônibus (15,02\%); Máquinas, aparelhos e materiais elétricos (11,49\%); Máquinas e equipamentos (5,61\%); e por último, o efetivo de bovinos destinados à produção de leite e reprodução $(4,76 \%)$. Já com relação à composição da FBCF de origem interestadual no estado, os produtos com maior peso participativo foram: Automóveis, camionetas, utilitários, caminhões e ônibus (33,30\%); Máquinas, aparelhos e materiais elétricos (29,03\%); Máquinas e equipamentos $(15,06 \%)$; Outros equipamentos de transporte $(11,91 \%)$ e Produtos de metal (5,49\%) (FUNDAÇÃO JOÃO PINHEIRO, 2011). A Tabela 10 decompõe o investimento total do período analisado (2005-2009) de origem interna e importado (interestadual e internacional) nos 11 produtos típicos de formação de capital fixo.

Com relação aos investimentos de origem internacional chama a atenção na interpretação da Tabela 10 o peso significativo que os segmentos de maior valor tecnológico, como o de Máquinas, aparelhos e materiais elétricos; e o de Máquinas e equipamentos possuem na participação relativa da FBCF de origem internacional: 42,50\% e 27,23\%, respectivamente. Embora na última década a indústria mineira tenha experimentado um crescimento interno na participação dos bens de capital e duráveis de consumo (e em termos corrente a produção interna seja bem maior do que a contribuição importada interestadual e internacional), esse crescimento ainda não foi suficiente frente às transformações do estado, o que evidencia a necessidade de importação principalmente por que os bens mais elaborados tecnologicamente ainda são oriundos do exterior. Assim, o que se percebe é que a modernização e o suprimento do parque industrial mineiro ligado à indústria de bens de capital vêm se fazendo, paulatinamente, através da importação de componentes para a produção. A substituição gradativa de importações de bens de maior valor agregado e com maior conteúdo tecnológico por bens da mesma natureza, só que produzidos internamente, ainda representa uma necessidade industrial da economia mineira (DINIZ; SOUZA, 2010). De fato, o desenvolvimento do setor de bens de capital configura-se em um fator importante para o aperfeiçoamento do Sistema de Inovações (SI) de Minas Gerais. Como bem observou o Instituto de Estudos para o Desenvolvimento Industrial: "o setor de máquinas e equipamentos [e o de aparelhagem elétrica] serve como meio de propagação de avanços tecnológicos internos, e 
assim do nível [quantitativo e qualitativo] de investimento.” (IEDI, 2005 apud NASCIMENTO, 2006, p.31).

Tabela 10 - Composição relativa (em \%) das 11 atividades/setores em termos da origem da FBCF para o total do período analisado (2005-2009)

\begin{tabular}{l|c|c|c}
\hline \multicolumn{1}{c|}{ Atividades/Setores } & $\begin{array}{c}\text { Contribuição } \\
\text { Importada } \\
\text { Internacional }\end{array}$ & $\begin{array}{c}\text { Contribuição } \\
\text { importada } \\
\text { interestadual }\end{array}$ & $\begin{array}{c}\text { Contribuição } \\
\text { interna }\end{array}$ \\
\hline $\begin{array}{l}\text { Outros produtos da agricultura, } \\
\text { silvicultura e exploração florestal }\end{array}$ & 0,81 & 1,02 & 1,87 \\
\hline Bovinos & 0,20 & 0,07 & 4,76 \\
\hline Outros produtos da pecuária e pesca & 0,00 & 0,18 & 0,26 \\
\hline Produtos de metal & 2,19 & 5,49 & 2,14 \\
\hline Máquinas e equipamentos & 27,23 & 15,06 & 5,61 \\
\hline $\begin{array}{l}\text { Máquinas, aparelhos e materiais } \\
\text { elétricos }\end{array}$ & 42,50 & 29,03 & 11,49 \\
\hline $\begin{array}{l}\text { Automóveis, camionetas, utilitários, } \\
\text { caminhões e ônibus }\end{array}$ & 15,15 & 33,30 & 15,02 \\
\hline Outros equipamentos de transporte & 11,40 & 11,91 & 0,58 \\
\hline $\begin{array}{l}\text { Móveis, produtos de madeira e artigos } \\
\text { diversos }\end{array}$ & 0,51 & 3,92 & 1,27 \\
\hline Construção & - & - & 56,70 \\
\hline Serviços prestados às empresas & - & 0,03 & 0,30 \\
\hline Total & $\mathbf{1 0 0 , 0 0}$ & $\mathbf{1 0 0 , 0 0}$ & $\mathbf{1 0 0 , 0 0}$ \\
\hline
\end{tabular}

Fonte: Elaboração própria com base no banco de dados e nas planilhas de evolução da FBCF pela FUNDAÇÃO JOÃO PINHEIRO (2011).

Da mesma forma, analisando o peso dos investimentos de origem interestadual percebe-se uma preponderância dos segmentos com maior valor tecnológico incorporado: Automóveis, camionetas, utilitários, caminhões e ônibus (33,30\%); máquinas, aparelhos e materiais elétricos $(29,03 \%)$; máquinas e equipamentos $(15,06 \%)$ e outros equipamentos de transporte $(11,91 \%)$. No caso, sobretudo, dos bens de capital referentes à fabricação de máquinas, equipamentos e aparelhagem elétrica, pode-se dizer que boa parte desses investimentos no estado foram oriundos do estado de São Paulo (ALMEIDA; SANTOS; NEUENSCHWANDER, 2014). De fato, Minas Gerais 
não conseguiu internalizar os elos "mais nobres" das cadeias nacionais de produção e acabou configurando-se como um centro periférico industrial de "segunda grandeza" que apresenta, muitas vezes, uma relação subordinada ao estado de São Paulo e aos núcleos mais dinâmicos do capitalismo global. Um bom exemplo disso é que o estado tradicionalmente se caracterizou na exportação dos "elos inferiores" da cadeia mineral e metalúrgica (em caráter complementar) para a economia paulista e na importação dos "elos superiores" (máquinas, equipamentos e materiais elétricos), e isto prejudicou o avanço dos bens com maior valor tecnológico na dinâmica interna da economia mineira (LEMOS, 2002), mesmo com os avanços ocorridos no final da última década na fabricação de eletrônicos no entorno de Belo Horizonte e em Santa Rita do Sapucaí com o desenvolvimento do Arranjo Produtivo Local (APL) na região (SINDVEL, 2007).

Mudando um pouco o foco da análise para o uso e não para a origem da FBCF, pode-se afirmar que, uma parcela significativa dos investimentos em Minas Gerais ainda se concentra nos segmentos de mineração e siderurgia, até em virtude do que foi explicitado no parágrafo anterior. Do total da FBCF estadual no período 2005-2009 (cerca de R\$ 209.943,72 milhões), estima-se que a mineração tenha sido responsável por $22 \%$ (ou $\mathrm{R} \$ 46.523,52$ milhões), enquanto a siderurgia tenha participado com 19\% dos aportes (ou R\$39.889,30 milhões) (SEDE, 2010).

Como forma de salientar o peso da indústria de mineração em Minas Gerais, pode-se afirmar que o estado responde por 35\% do total da produção mineral brasileira no período de análise, sendo o maior produtor brasileiro de Ferro. O estado também se destaca como o maior produtor nacional de Fosfato, Ouro, Tantalita e Zinco e o maior produtor de Nióbio do Mundo. Além disso, as commodities minerais possuem um peso significativo no total das exportações estaduais. Todas estas informações justificam o elevado nível de investimento realizado pelo setor mineral (IBRAM, 2010). O Gráfico 1 abaixo traz a composição dos investimentos em termos percentuais em Minas Gerais no período 2005-2009 segundo os principais tipos de minerais explorados na economia mineira, destacando o maior peso dos investimentos para a extração do Ferro. Tais informações foram retiradas do Instituto Brasileiro de Mineração (IBRAM). 
Gráfico 1 - Composição dos Investimentos (em \%) dos principais minerais explorados na economia mineira no período 2005-2009

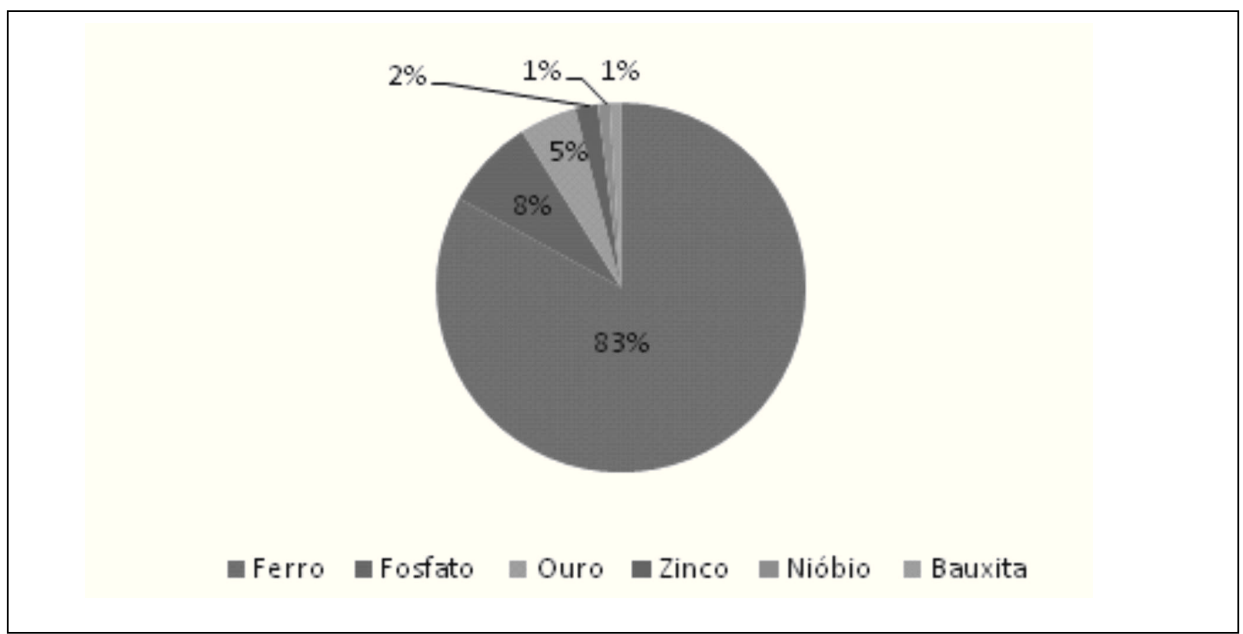

Fonte: IBRAM (2010) p.4

Por fim, ainda em relação aos investimentos da Indústria Extrativa Mineral, pode-se dizer que os principais projetos nos setores de Siderurgia e Mineração iniciados no período de análise (2005-2009), corresponderam ao projeto Apolo, que consiste na implantação de uma mina de minério de ferro pela CVRD (Companhia Vale do Rio Doce); a expansão da Mineração Casa de Pedra, que é uma mina localizada em Congonhas e que produz minério de ferro de elevado teor, pela CSN (Companhia Siderúrgica Nacional); a exploração de ouro em Riacho dos Machados no norte de minas pela Carpathian; e o desenvolvimento da mineração em Conceição do Mato Dentro localizada na região central do estado pela Anglo Ferrous (SEDE, 2010).

\section{CONCLUSÕES E CONSIDERAÇÕES FINAIS}

Este artigo procurou mapear, detalhar e dimensionar os investimentos (ou a Formação Bruta de Capital Fixo) realizados em Minas Gerais durante o período 2005-2009. Do ponto de vista relacionado à apresentação das informações numéricas mapeadas, as principais conclusões do estudo foram: 
- A taxa média de investimento anual em Minas Gerais, como proporção do PIB, no período total analisado foi de $17,25 \%$. Além disso, a taxa de investimento aumentou a sua participação no PIB quando a taxa de juros apresentou trajetória decrescente, indicando, portanto, aderência à teoria econômica no período 2005-2008;

- $\quad$ Especificamente em relação ao ano de 2009, observa-se inflexão na FBCF total do estado em razão da ocorrência da crise econômica mundial no final de 2008 e com impacto (efeito "contágio") na economia mineira, o que pode ser explicado pelo desenvolvimento mais recente da teoria do investimento que considera os condicionantes externos como fatores intervenientes no nível da FBCF. Todavia, enquanto o investimento privado em 2009 deteriorou-se, o investimento público seguiu trajetória contrária e ampliou a sua participação, indicando alguma relação com a teoria keynesiana que prevê a intervenção estatal na suavização dos efeitos de possíveis períodos conturbados e de instabilidade econômica;

- Os investimentos internos ofertados corresponderam a 79,40\% do total da FBCF no período, com destaque para o setor da construção civil (que correspondeu a 56,70\% dos investimentos de origem interna);

- Os investimentos interestaduais participaram em $16,18 \%$ do total da FBCF no período, com maior peso para o setor de Automóveis, camionetas, utilitários, caminhões e ônibus $(33,30 \%$ dos investimentos interestaduais);

- $\quad$ A contribuição importada internacional correspondeu a 4,42\% do total da FBCF no período, com maior peso para o setor de maior conteúdo tecnológico incorporado, o setor de Máquinas, aparelhos e materiais elétricos (42,50\% dos investimentos internacionais);

- $\quad$ O investimento público, entendido como a contribuição das empresas controladas somente pela esfera estadual mais a administração direta, correspondeu a $19,50 \%$ do total da FBCF no período. Desses, 12,41\% faz referência a contribuição das empresas controladas pelo estado, contra 7,08\% referente à participação da administração direta no total da FBCF; 
- $\quad$ A CEMIG e a COPASA foram as duas empresas controladas pelo estado com maior peso na FBCF total durante o período: 8,64\% e 2,51\%, respectivamente;

- Os setores de mineração e siderurgia participaram, respectivamente, em $22 \%$ e $19 \%$ da utilização da FBCF do período analisado. Destacaram-se uma série de projetos com implantação/expansão de minas de extração mineral, sobretudo, de minério de ferro;

- $\quad$ Em relação aos investimentos em infraestrutura no estado, os resultados demonstraram uma maior participação no PIB desses investimentos na economia mineira comparativamente a economia brasileira no período 2008-2010: 4,38\% contra 2,45\%. Os resultados estimados/projetados para Minas Gerais foram mais expressivos do que no Brasil para os agrupamentos de telecomunicações, energia elétrica e saneamento;

- $\quad$ Por fim, a realização do estudo permitiu a identificação de dois problemas estruturais importantes para o desenvolvimento da economia mineira, o que pode servir como foco de futuras políticas públicas condizentes com as inconsistências identificadas. O primeiro problema diz respeito às necessidades de investimentos em infraestrutura de transporte (sobretudo rodoviário) em face ao aumento na frota de veículos no estado, a baixa participação do investimento em infraestrutura de transporte como proporção do PIB em Minas Gerais e a situação precária das estradas e rodovias estaduais. O segundo problema identificado refere-se à fragilidade do setor interno de produção de bens de capital (sobretudo o de fabricação de Máquinas, aparelhos e materiais elétricos), carente em modernização e pautado em importações (internacional e interestadual). Esta fragilidade da economia mineira acaba caracterizando o estado como um centro periférico industrial de "segunda potência", pois contribui para que o excedente operacional do estado acabe capturado pelos núcleos mais dinâmicos do capitalismo global e, dentro do contexto nacional, pelo centro periférico de "primeira ordem" (o estado de São Paulo). 


\title{
GROSS FIXED CAPITAL FORMATION IN MINAS GERAIS DURING THE PERIOD 2005-2009: BOTTLENECK IN HIGHWAY INFRASTRUCTURE AND MORE ELABORATED CAPITAL GOODS PRODUCTION
}

\begin{abstract}
This paper aims to carry out a mapping of investments or, in more technical language, the Gross Fixed Capital Formation (GFCF) in Minas Gerais in the period 2005-2009. The methodology used for this purpose is to reference the results of the calculation of GFCF by FJP and other supplementary data sources. Briefly, it is intended to detail the investments with respect to their origin, use and composition; quantifying public investments by the state; analyze the weight of investments in infrastructure and identify potential bottlenecks for the establishment of public policies. Wherever possible, we sought to characterize the behavior of GFCF by means of economic theories of the determinants of investment.

Keywords: Investment, Gross Fixed Capital Formation (GFCF), Determinants of Investment, Infrastructure, Public Investment, Economy of Minas Gerais.
\end{abstract}

JEL Classification: E22, E62, G11, G31

\section{REFERÊNCIAS}

ABTC. Gastos de Infraestrutura: como vamos? Brasília: Associação Brasileira de Logística e Transporte de Carga, 2009.

ALMEIDA, Thiago Rafael de; SANTOS, Maria Aparecida Sales; NEUENSCHWANDER, Joana de Oliveira. Evolução da estrutura produtiva de Minas Gerais: uma análise do comportamento da agropecuária e indústria estadual com ênfase na década (2000-2010). In: GUIMARÃES, Alexandre Queiroz. Ideias em Desenvolvimento para a promoção do avanço econômico em Minas Gerais. Belo Horizonte: Fundação João Pinheiro, 2014. 
BANCO CENTRAL. Consulta a taxa Selic. Brasília: Banco Central do Brasil, 2010. Disponível em: <http:/www.bcb.gov.br/?SELICTAXA.> Acesso em: out. 2014.

BDMG. Infraestrutura, Sustentando o Desenvolvimento: Os gargalos e os Espaços para Intervenção Estadual. Belo Horizonte: Banco de Desenvolvimento de Minas Gerais S. A - Minas Gerais do século XXI, volume III, 2004.

BNDES. Taxa de juros de Longo Prazo - TJLP. Rio de Janeiro: Banco Nacional do Desenvolvimento, 2010. Disponível em: $<$ http://www.bndes. gov.br/SiteBNDES/bndes/bndes_pt/Institucional/Apoio_Financeiro/Custos_Financeiros/Taxa_de_Juros_de_Longo_Prazo_TJLP/>. Acesso em: out. 2014.

BRASIL. Programa de Aceleração do Crescimento 2007-2010: romper barreiras e superar limites de investimento em infraestrutura. Apresentação inaugural do programa em 22.1.2007. Ministra Dilma Rousseff. Brasília: Casa Civil da Presidência da República, 2007. Disponível em: <www.pac. gov.br>. Acesso em: out. 2014.

CAMPOS NETO, Carlos Alvares da Silva; SOARES, Ricardo Pereira; FERREIRA, Iansã Melo; POMPERMAYER, Fabiano Mezadre; ROMMINGER, Alfredo Erick. Gargalos e Demandas da Infraestrutura Rodoviária e os investimentos do PAC: Mapeamento IPEA de obras Rodoviárias. Brasília: Instituto de Pesquisa Econômica Aplicada (IPEA), texto para discussão ${ }^{\circ}$ 1592, 2011.

CARVALHO, Fernando Cardim de. Políticas econômicas para Economias Monetárias. In: LIMA, Gilberto Tadeu; SICSÚ, João; PAULA, Luiz Fernando de (Org). Macroeconomia Moderna: Keynes e a Economia Contemporânea. Rio de Janeiro: Ed. Campus LTDA, 1999. p.258-283.

DAVIDSON, Paul. Colocando as evidências em Ordem: Macroeconomia de Keynes versus Velho e Novo Keynesianismo. In: LIMA, Gilberto Tadeu; 
SICSÚ, João; PAULA, Luiz Fernando de (Org). Macroeconomia Moderna: Keynes e a Economia Contemporânea. Rio de Janeiro: Ed. Campus LTDA, 1999. p.35-64.

DINIZ, Gustavo Figueiredo Campolina; SOUZA, Osmar Tomaz de. Indústria Mineira: Mudanças estruturais e Aglomerações territoriais. Porto Alegre: XIII Encontro Regional de Economia -ANPEC Sul, 2010. p. 1-20.

DOMINGUES, Edson Paulo; MAGALHÃES, Aline Souza; FARIA, Weslem Rodrigues. Infraestrutura, Desigualdade Regional, Crescimento e Desenvolvimento econômico: uma projeção dos impactos dos investimentos do Programa de Aceleração do Crescimento (PAC) em Minas Gerais. Belo Horizonte: pesquisa e planejamento econômico (ppe), 2009. v.39, n.1, p. 121-158.

FRISCHTAK, Claúdio R. O investimento em infra-estrutura no Brasil: Histórico Recente e perspectivas. Brasília: Pesquisa e Planejamento Econômico (PPE), Instituto de Pesquisas Econômicas Aplicada (IPEA), 2008.

FUNDAÇÃO JOÃO PINHEIRO. Formação Bruta de Capital Fixo (FBCF) em Minas Gerais. Belo Horizonte: Fundação João Pinheiro Centro de Estatística e Informações, 2011. p.1-55.

GRASEL, D. Determinantes do investimento no Brasil: 1980/90. Dissertação de Mestrado (Mestre em Engenharia de Produção). Departamento de Engenharia de Produção de Sistemas. Florianópolis: Universidade Federal de Santa Catarina, 1996.

GRASEL, Dirceu; SANTANA, Edvaldo Alves de. Determinantes do Investimento no Brasil: 1980/90. Revista Textos de Economia. Florianópolis: Universidade Federal de Santa Catarina, 1995.

IBRAM. A Indústria da Mineração em Minas Gerais. Brasília: Instituto Brasileiro de Mineração, 2010. 
JACINTO, Paulo de Andrade; RIBEIRO, Eduardo P. Co-integração, Efeitos Crowding-in e Crowding-out entre Investimento Público e Privado no Brasil: 1973-1989. Passo Fundo: Teor. Evid. Econ, 1998. v.6, n.11, p. 143-156.

KEYNES, John Maynard. A teoria geral do emprego, do juro e da moeda. São Paulo: Atlas, 1982. cap.3 e 11.

LEMOS. Mauro Borges. Integrando a indústria para o futuro. In: MINAS GERAIS do Século XXI. Belo Horizonte: Rona, 2002.

MIGLIOLI, Jorge. Kalecki: A dinâmica das Economias Capitalistas. In: . Acumulação de Capital e Demanda Efetiva. São Paulo: T. A. Queiroz, Editor, LTDA, 1986. p.275-296.

MORAIS, Reinaldo Carvalho de; GUIMARÃES, Alexandre Queiroz. Desafios ao aumento da competitividade em Minas Gerais. In: G U I MARÃES, Alexandre Queiroz (Org). Ideias em Desenvolvimento para a promoção do avanço econômico em Minas Gerais. Belo Horizonte: Fundação João Pinheiro, 2014.

NASCIMENTO, Monike Gomes do. Investimento em capital fixo no Brasil: Uma análise de 1991 a 2003. 2006. Monografia (Graduação em Ciências Econômicas). João Pessoa: Universidade Federal da Paraíba, 2006.

PASTORE, José. Empregos na Infraestrutura: Potencial e Barreiras. São Paulo: Universidade de São Paulo, 1998.

PEDROSO, Rodrigo; VIRI, Natália. Projeções de racionamento provocam "pânico", diz ONS. São Paulo: Valor Econômico, 2014.

PINDYCK, R e SOLIMANO, A. A Instabilidade Econômica e o Investimento Agregado. NBER, Macroeconomia Anual, 1993.

RESENDE, M. F. C; AMADO, M. A. Liquidez internacional e ciclo reflexo: algumas observações para a América Latina. São Paulo: Revista de Economia Política, jan/mar, 2007. v.27, n.1, p. 41-59. 
SANCHES, Nathalie Gimenes; ROCHA, Fabiana. Investimentos Estaduais Públicos e Privados: "bens" substitutos ou complementares?. São Paulo: Economia Aplicada, 2010. v.14, n.2, p.211-223.

SEDE. Indústria de Transformação e setor extrativo mantêm crescimento da produção em Minas. Belo Horizonte: Secretaria de Estado de Desenvolvimento Econômico (SEDE) - Governo de Minas, 2010.

SEPLAG. Relatório Resumido da Execução Orçamentária - Demonstrativo do Resultado Primário. Belo Horizonte: Secretaria de Estado de Planejamento e Gestão (SEPLAG) - 2005-2009 - Governo do Estado de Minas Gerais, 2010.

SEPLAG. Volume III - Orçamento de Investimento das Empresas Controladas pelo Estado. Belo Horizonte: Secretaria de Estado de Planejamento e Gestão (SEPLAG) - 2005-2009 - Governo do Estado de Minas Gerais, 2010.

SINDVEL. Plano de Desenvolvimento do Arranjo Produtivo Eletroeletrônico de Santa Rita do Sapucaí. Belo Horizonte: Sindicato das Indústrias de Aparelhos Elétricos, Eletrônicos e similares do Vale da Eletrônica, 2007.

TEIXEIRA, Luciene Pires; CARVALHO, Fátima Marília de Andrade de. A Construção Civil como instrumento do Desenvolvimento da economia brasileira. Curitiba: Revista Paranaense de Desenvolvimento ${ }^{\circ} 109$, 2005. p. 09-26.

TORRES, Carlos Eduardo da Gama. Equilíbrio Geral Computável e Infraestrutura de Transportes: uma análise para Minas Gerais. Belo Horizonte: Universidade Federal de Minas Gerais (UFMG) - Centro de Desenvolvimento e Planejamento Regional (CEDEPLAR), 2006.

VILAR, Adriana Aparecida Isola; CORREA, Lucilena Ferraz Castanheira; CAMPOS, Mabel Jaqueline Carmona de. Política de investimento ótimo de uma firma: uma aplicação empírica para dados macroeconômicos do Brasil a partir de 1991. Recife: PIMES, 2004. 